
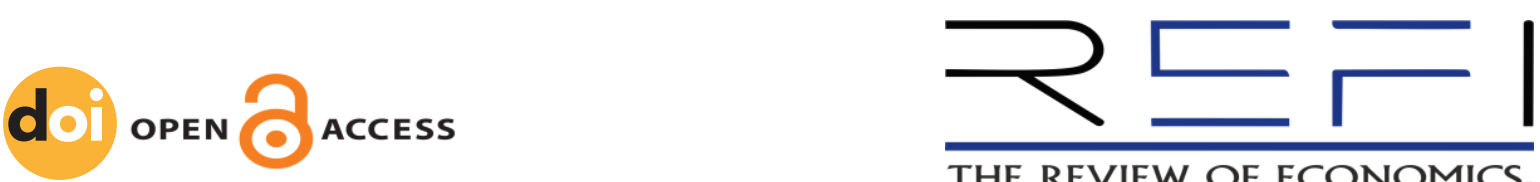

\title{
Blockchain as a Determinant of Bitcoin Value
}

\author{
By ROBERT WOJCIECH WŁODARCZYK*
}

\begin{abstract}
The article discusses the determinants of the bitcoin (BTC) price value, with particular emphasis on blockchain technology. The method of critical analysis of the literature on the subject was applied, and the state of knowledge in this field was established by juxtaposing different views of researchers on the BTC price value. It has been proven that BTC, being unquestionably a financial innovation, has been subjected to a free valuation of its price in the markets. While observing the development of BTC quotations, potential causes of numerous fluctuations in its market valuation were searched for.

The article shows that the expectations related to the use of BTC are relatively highly valued by investors in modern financial markets. A more efficient currency, competition between currencies or the provision of new technological solutions may bring benefits to markets and economies, which, discounted at the present time, generate a certain value. Therefore, the paper shows that the BTC value creation mechanism is therefore different from that of fiat currencies. It has also been confirmed that the promotion of one of the most popular distributed data registers, which is blockchain, is of great value for BTC. BTC has led to the development of blockchain technology that is used in various segments of the economy.

Basing BTC's operation on a public data register is the strength of the entire BTC network, but it also brings many risks and uncertainties. Further, research should focus on searching for the economic effects that result from the development of blockchain technology in modern economies.
\end{abstract}

JEL Classification: E51, F30, O16.

Suggested citation: Włodarczyk, R.W. (2020). Blockchain as a Determinant of Bitcoin Value. The Review of Economics, Finance and Investments, 1(1), 8-14.

\section{INTRODUCTION}

For investors, cryptocurrencies are a new type of financial instrument that has appeared on global markets. Currently, they are in the center of attention of economic practitioners and economic theorists. Cryptocurrencies appeared in economies as a manifestation of the ongoing digital transformation. They are the main cause of intensive changes at the interface between the real economy and finance, leading to the modern form of the financial revolution, the essence of which is to combine freedom with technological progress. Cryptocurrencies are a digital record, based on cryptography and operating in an appropriate IT environment. You can also define them as some special form of virtual currencies, which in turn are treated as another form of money. Much attention is also paid to the value of cryptocurrencies and its determinants, as well as the effects of their implementation into financial and economic systems.

Currently, one of the most important and widely discussed cryptocurrencies is bitcoin. He was known mainly due to the new functionalities he was discovering, spectacular increases in the rate, as well as a sharp increase in turnover on financial markets. On the one hand, this has brought substantial profits to the original bitcoin owners, and on the other, it has become another attractive investment opportunity. First of all, it should be emphasized that bitcoin inadvertently became the first major implementation of blockchain technology, and also appeared on the currency and derivative markets. All this triggered a wide discussion about not only its applications in economic practice, but also its effects

\footnotetext{
${ }^{*}$ Robert Wojciech Włodarczyk, Rector of Podhale State College of Applied Sciences in Nowy Targ (Poland), Associate Professor at Cracow University of Economics (Poland); ORCID: 000o-0001-7610-6504; email: ror20@wp.pl.
} 
on the economy in the long run. Various groups joined this multilateral discussion, i.e. innovators in the world of finance, bankers, IT specialists, the world of industry, scientists, state authorities, regulators, lawyers, anti-corruption services, as well as small investors. There is currently a debate about the possibility of bitcoin, or more generally cryptocurrencies, functioning as national or even international currencies, the effects of replacing the currently known fiat money with cryptocurrencies, and the impact of these changes on the productivity of the industry and the functioning and efficiency of the economy. Blockchain technology is inextricably linked with bitcoin. In the simplest definition, it can be presented as a distributed set of transactions carried out by network users. This technology was used for the first time in 2009 as part of the bitcoin cryptocurrency and is still used today to record transactions made with it. This system operates in a distributed network and serves the exchange of values between the users of this network. Although blockchain technology has been around for more than 12 years, it has only recently been talked about. Hence, experts agree that its first application was participation in the creation of cryptocurrencies. Originally, blockchain technology was the distributed backbone of the bitcoin system. Currently, several thousand cryptocurrencies are already available to the public. While the general idea of their operation is similar, they can be divided into several types depending on the implementation details. They determine the possibilities of use and specific features of individual cryptocurrencies. Today, the possibilities of blockchain technology go beyond the cryptocurrency markets, and the basic mechanisms of its functioning have also found application in other business solutions. One of the first industries to take advantage of these opportunities was the financial market, including the banking sector. Currently, other sectors and industries that want to benefit from the advantages of new blockchain-based technology are also conducting intensive research and development activities, using innovative blockchain technology solutions, and testing the potential use of blockchain. Blockchain transactions are transparent and without intermediaries. Anyone can trace them from anywhere on the web.

Blockchain as a decentralized and distributed database creates new threats and challenges. The problem with achieving complete security within blockchain technology is that it is completely new. Most initiatives related to this technology are in the early stages of development and often operate as a pilot solution or are in the early stages of implementation. Moreover, it should be remembered that in Poland this technology still requires many legal regulations. It is believed that blockchain is a technology that may revolutionize many industries in the world in the near future. New digital technologies, including blockchain, are changing the conditions for the functioning and competition of business entities in various industries and sectors of the economy - from the financial sector through the processing industry to trade. The basic idea of blockchain technology is the use of networks and computer algorithms to ensure credibility, originality and time savings in the transmission of information between parties. Blockchain technology as an innovative solution can play an important role in the economic process, thus contributing to economic development. According to experts, blockchain will change the way companies operate in almost all industries within a decade. There is no doubt that this technology will be systematically developed, also outside the area of digital payments. It is already slowly being used in healthcare, politics, administration, as well as on the real estate and energy markets.

The main goal of the article is to present the issues of cryptocurrencies, including the value of bitcoin, with particular emphasis on the importance of blockchain technology.

This article includes five parts: introduction, literature review, data and research methodology, empirical analysis - results and discussions, and concluding remarks.

\section{LITERATURE REVIEW}

After the appearance of bitcoin - the first cryptocurrency in the world - a wide discussion on its essence and economic significance arose in the literature on the subject. Bitcoin has been classified into the cryptocurrency category and has become the subject of many studies, often of a practical nature. Its dynamic entry into financial markets contributed to the building of the theoretical foundations for the functioning of this group of assets. The debate on cryptocurrencies and bitcoin is inextricably linked with the digital transformation of economies taking place in various parts of the world, even referred to 
as the digital revolution (Gawrysiak, 2020, p. 25). This process accelerated at the turn of the 20th and 21st centuries, affecting many industries and sectors and affecting the structure of production and employment (Włodarczyk, 2011, p. 527-550). The basis of these changes was the IT language, algorithms, robots and dematerialized value. The pace of spreading new digital technologies is much faster than all inventions from previous industrial revolutions (Łaszek, 2018, p. 6-7). The broadly understood business is digitizing (Poniatowska-Jaksch, Sobiecki, 2020, p. 24). Digital transformation is associated with the opportunity for economic development, improvement of the quality of life, and the implementation of democratic and emancipatory ideals (Śledzewska, Włoch, 2020, p. 10). An additional impulse for the occurrence of this type of change is the currently ongoing global COVID-19 pandemic, which not only modifies our daily functioning, but also re-evaluates many trends, including technological ones. One can even formulate a further conclusion that, paradoxically, it was the pandemic that contributed to the acceleration of digitization, especially in the financial area. Digitization is treated as a megatrend that changes the nature of competition and enables the achievement of economies of scale much faster than in the traditional economy. Digitization causes financial inclusion (Spencer, 2019). It changes the financial systems of many countries. Thanks to it, new forms of money are created and the role of cash in financial intermediation is reduced (Kabza, 2020).

Digital money is a value that is written in computer language (digitally) (Cunningham, Fröschl, 1999, p. 143-144). It is also defined as a digital version of cash managed by a private key that allows for cross-border and immediate transfer of value. Digital money is a value that makes digital payments possible. Currently, blockchain technology is increasingly used in its construction, in which a chain of successive blocks described with appropriate cryptographic signatures is used to save various information, e.g. the owner or the transfer of digital units. Blockchain has given digital money a new quality and various uses. In turn, digital currencies (stablecoins) are currencies whose value depends on trust in the issuer, similar to fiat money, or on the value of various real assets, using blockchain technology or other data registers. Stablecoins covered in currencies operating on the market are a promising innovation in the field of payment processing, as they combine all the advantages of digital money with the stability of the existing currency.

It is also important in the context of the ongoing discussion to explain the concept of cryptocurrency. The concept of cryptocurrency was first described by Wei Dai on the cypherpunks mailing list in 1998 (Lis Markiewicz, Nowak, 2015, p. 30). At that time, it was presented as a new form of money that used cryptography instead of a central bank in the process of issuing and controlling transactions, as is the case with most of today's fiat currencies. The notion of this concept became more widely known only after 2008, when the first bitcoins were issued. It should be noted that along with the huge success of bitcoin on financial markets, new cryptocurrencies began to appear, new mechanisms for their creation, as well as their various applications in the management process. All this translated into a great variety of interpretations of cryptocurrencies. As a result of the ongoing debate, the concept has become imprecise and ambiguous. In the literature on the subject, there are even voices that the term "cryptocurrency" is inappropriate for this type of instruments and a much better name would be the term "cryptographic currency" (Szymankiewicz, 2014, p. 22). Despite these terminological doubts, it is worth sticking to the traditional name, if only because of its social and scientific acceptance. The achievements to date explain this group of assets in various ways. Some researchers treat cryptocurrency, also known as virtual money, as a distributed, cryptographically encoded accounting system. The basis of this system are nodes containing wallets in which users store private keys to their cryptocurrencies. Private keys are responsible for security and preventing the multiple use of these units.

These prior empirical results allowed to assume the following research hypotheses:

- H1: Blockchain technology is an important determinant of bitcoin's value.

- H2: The increase in the value of bitcoin is due to the increasing number of new applications of blockchain technology in the economy. 


\section{DATA AND RESEARCH METHODOLOGY}

Bitcoin's quotation began in the financial markets much later than the first bitcoin dug. This means that initially bitcoins were not valued by the markets after they were mined. They were in private circulation and aroused curiosity rather than presented any value. Various situations are described, such as buying two pizzas for several thousand bitcoins or freely throwing away hard drives containing several thousand of then "worthless" bitcoins. These events represent the majority's initial attitude to bitcoin and its value at the time, which, from the perspective of today's valuations, shows the low level of understanding of bitcoin's potential even by its supporters.

The value of bitcoin started practically from zero. The turning point in the search for a market valuation of bitcoin was the setting of its first rate against the US dollar by the online New Liberty Standard exchange office. This exchange rate was first calculated on October 5, 2009, based on the cost of its extraction, and then amounted to USD / BTC 1,309.03, i.e. 1 US dollar was then paid 1,309.03 bitcoins. The lowest bitcoin was valued on December 17, 2009, when the exchange rate was USD / BTC 1,630.33. Although the first rate was established not on the basis of the law of supply and demand, but using the cost method, and more precisely on the basis of its extraction cost, it was a benchmark for the markets in the following years, and was also the basis for transactions on the market at that time. The first market valuation of bitcoin ( $\$ 0.063$ for 1 BTC) took place on August 17, 2010 on the Mt.Gox cryptocurrency exchange. As you can see, initially, the organization of bitcoin pricing was private and was not regulated in any way at the national level, hence numerous threats quickly appeared for people willing to engage in cryptocurrency markets.

\section{DISCUSSION}

The valuation of financial instruments is a complex and varied process. It can be done in an analytical and theoretical way, which is done by experts with the use of appropriate models, formulas and equations, or as a result of a subjective decision of the issuer or intermediary trading in given financial instruments. Determining the correct price of a financial instrument may also result from a properly functioning market mechanism. In fact, what the value of a financial instrument is depends on the timing of the valuation, the method used, and the method and entity that carries it out. The valuation process becomes even more complicated when it comes to financial innovation. In addition to the common problems with valuation, there are also additional ones, such as: the problem of defining the value of this innovation, its determinants, and the construction of new methods of price estimation.

Bitcoin, being unquestionably a financial innovation, has been subjected to a free valuation of its value in the markets. Observing the development of its quotation, it underwent numerous short-term phases of euphoria and the related sharp increases in price, as well as experienced many corrections of this value. It has become an object desired by investors and has been used, like most assets, for investment and speculative purposes. It was not even prevented by the fact that bitcoin was created by an unknown author for other purposes. It seems that many people took bitcoin as an opportunity to earn money and were not entirely interested in the course of fate or the evolution of this cryptocurrency in accordance with the goals set out in Satoshi's manifesto.

Looking at bitcoin from the point of view of the average investor, although not necessarily legally, it can be treated as one of the financial instruments found on the financial markets. The specificity of functioning on the markets results from its dematerialisation, although this is not something new for investors, as intangible trading takes place on stock exchanges. It must be admitted, however, that most exchanges have material equivalents of assets deposited in appropriate deposits, and in the case of bitcoin, due to its digital dimension, such a material alternative does not exist. The fact is, for some time now, investors have been pricing bitcoin in both spot and futures financial markets. Although it functions in a completely dematerialized form, the assigned value is a manifestation of not only its usefulness for investors, but also the discounted benefits from future applications in the economy. It is also interesting that various disruptions in the functioning of institutions that support bitcoin transactions, e.g. 
collapses of cryptocurrency exchanges, cyberattacks or bitcoin thefts, turned out to be relatively unfavorable factors for the value of bitcoin, while no such signals were observed from the operation of the bitcoin network itself.

The assessment of the form and mechanism of bitcoin operation allows us to assume that its value results from determinants other than the value of the functioning money. Bitcoin has the potential to replace current payment systems, which would result in enormous economic gains if its properties became widespread in the financial system. In addition, investors see it as the beginning of a wider process of introducing private digital currencies, competing with state money. This may mean the coexistence of private and state monetary units or the slow displacement of government money by bitcoin, which is considered more useful in today's economic conditions. Bitcoin, as a private currency issued by society, is free from the numerous disadvantages of state money and therefore adds value to the economy, equivalent to the absence of costs inherent in modern fiat money. The lack of a functioning entity that manages the money supply and efforts to maintain confidence in money is a saving that can add additional value to bitcoin as it appears in its valuation. The fact that there is no risk of undermining confidence in bitcoin, which can be done quite easily against traditional currencies, will be a factor in stimulating the market value of bitcoin.

The expectations related to the use of bitcoin are valued in modern financial markets, which confirms that they have value in the eyes of investors. A more efficient currency or competition between currencies can bring benefits to markets and economies, which when discounted for today generate a certain value. Bitcoin's value creation mechanism is therefore different from that of fiat currencies.

Ultimately, it must be remembered that trusting the internet bitcoin system, identifying its new uses and functionalities, influence the fluctuations in demand for bitcoin and thus affect its price, and therefore determine its value in practice. Bitcoin is characterized by only a certain level of trust and acceptance among a specific group of society, which in turn limits its usefulness and market value. Observation of the bitcoin market proves that increasing its public approval, mainly through new realworld applications, leads to increased value in the markets. Institutional and legal restrictions are not without significance for the valuation of bitcoin. On the one hand, they create strong barriers to access to trading, weaken the liquidity of assets or discourage prudent investors from entering this market, on the other hand, they generate undesirable risks causing excessive expectations as to the rates of return on investment in bitcoin, its volatility and instability in investors' assessment of the market situation. Observation of the bitcoin market proves that increasing its public approval, mainly through new realworld applications, leads to increased value in the markets.

\section{CONCLUding REMARKS}

The digital revolution is a process of change currently taking place in many economies in terms of automation, digitization and artificial intelligence. According to many studies, it will affect the acceleration of economic growth and productivity in the next several dozen years, which should translate into an increase in welfare and living standards. However, it will not do without negative consequences for individual sectors, as digitization will also result in changes in the relative prices of products, services and assets. It will also affect the valuation of production factors, so changes in the labor and capital markets should be expected. The importance of knowledge as a separate productive factor will clearly increase, along with labor and capital, which will be desired and widely used by the emerging information society.

Bitcoin is a manifestation of the digital revolution taking place. Although it directly affects the financial sector, it leaves its mark on many other sectors of the economy. The advent of the Bitcoin protocol played a large role in the spread of cryptocurrencies in society and financial markets. First of all, great importance should be attributed to the fact that this protocol has become available to everyone on an open source basis, it has an incentive mechanism to authenticate transactions (initially in the form of a reward, i.e. bitcoins mined, later as a payment in the form of bitcoins from the fees paid. transactions), while the acquisition of subsequent units is based on the computational difficulty of mathematical puzzles correlated with the computing power of the network. The bitcoin network has many security 
features, and one of the most important is that the entity that presents the private key is verified by this network as the rightful owner of the bitcoin.

The author of the bitcoin project is a member of the metzdowd.com mailing list, hiding under the pseudonym Satoshi Nakamoto. It was there that, on October 31, 2008, the Satoshi Nakamoto manifesto was published, which describes the specific principles of the bitcoin network. The first transaction on the Bitcoin network was made nine days later, on January 12, 2009, counting from the approval of the genesis block. Looking chronologically at the development of bitcoin, it can be said that it goes from a curiosity to a full-fledged medium of exchange. In the light of extensive work on official digital currencies carried out by central banks in many countries around the world, bitcoin may be considered the first unofficial digital currency in the world. Bitcoin can be not only a payment unit, but also a payment system. The bitcoin project has brought about profound changes in the perception of modern finance and digital currencies. It triggered huge technological changes and progress in this area, as well as the search for new applications and functionalities.

Bitcoin appeared in cyberspace with originally written source code. Many other similar cryptocurrencies were created on the basis of the bitcoin code. In addition to them, cryptocurrencies with their own source code have also been created that are not related to bitcoin. It seems that bitcoin's success cannot be so directly transferred to other cryptocurrencies, because the value that the markets have priced based on the properties of bitcoin cannot be duplicated. Rather, financial markets price all known bitcoin functionalities, so all cryptocurrencies based on bitcoin's source code cannot get the same value as bitcoin, as this has already been discounted by the market in the form of bitcoin pricing. Non-bitcoin cryptocurrencies have the chance to obtain higher values if new uses for them are discovered, both for cryptocurrencies based on bitcoin source code and code separate from bitcoin source code. For this reason, many cryptocurrencies are disappearing from the market, because the low interest in them on the market results from the lack of new utility, so far unknown to investors and users. However, the success of cryptocurrencies to date is invaluable. One may even be tempted to say that the emergence of cryptocurrency was the most spectacular result of implementing blockchain innovation in the financial system (Kułakow, 2019, p. 95-96).

\section{REFERENCES}

Cunningham, P., Fröschl, F. (1999). Electronic Business Revolution. Opportunities and Challenges in the 21st Century. Springer. Gawrysiak, P. (2020). Cyfrowa rewolucja. Rozwój cywilizacji informacyjnej. Warszawa: Wydawnictwo Naukowe PWN.

Kabza, M. (2020). Nowy, cyfrowy pieniądz banku centralnego. Obserwator finansowy.pl, downloaded: https://www.obserwatorfinansowy.pl/tematyka/rynki-finansowe/nowy-cyfrowy-pieniadz-banku-centralnego/.

Kułakow, M.W. (2019). Waluty cyfrowe, gwałtowny rozwój teraz, potencjalne zagrożenie w przyszłości. [w:] J.M. Osipow, A.Z. Nowak (ed.). Rewolucja cyfrowa. Wyzwania. Problemy. Perspektywy rozwoju. Kraków: Wydawnictwo Naukowe Wydziału Zarządzania Uniwersytetu Warszawskiego.

Łaszek, A. (2018). E-rozwój. Cyfrowe technologie a gospodarka. Warszawa: Raport Forum Obywatelskiego Rozwoju.

Lis Markiewicz, P., Nowak, Sz. (2015). Bitcoin. Przyszłość inwestowania. Warszawa: Wydawnictwo Naukowe PWN.

Nowicka, K., (red.), (2019). Biznes cyfrowy: Perspektywa innowacji cyfrowych. Warszawa: Oficyna Wydawnicza SGH.

Poniatowska-Jaksch, M., Sobiecki, R., (ed.), (2020). Cyfryzacja a przedsiębiorstwo. Warszawa: Oficyna Wydawnicza SGH.

Śledziewska, K., Włoch, R. (2020). Gospodarka cyfrowa. Jak nowe technologie zmieniają świat. Warszawa: Wydawnictwo Uniwersytetu Warszawskiego.

Spencer, M. (2019). Wpływ cyfrowej rewolucji na dobrobyt. Obserwator finansony.pl, 15.07.2019, downloaded: https://www.obserwatorfinansowy.pl/bez-kategorii/rotator/wplyw-cyfrowej-rewolucji-na-dobrobyt.

Szymankiewicz, M. (2014). Bitcoin. Wirtualna waluta internetu. Gliwice: Helion.

Włodarczyk, R.W. (2011). Zróżnicowanie sektorowej struktury pracujących w strefie euro. Ekonomista, 4, 527-550. 
CONFLICT OF INTEREST:

The authors declare that they have no material or financial interests associated with the research presented in this article. The authors declare that the study was conducted in the absence of any commercial or financial relationship giving rise to a conflict of interest.

\section{COPYRIGHT AND LICENSE:}

\section{(c) (1) $\Theta$}

This article is published under the terms of the Creative Commons

Attribution - NoDerivs (CC BY-ND 4.0) License

http://creativecommons.org/licenses/by-nd/4.0/

Published by Podhale State College of Applied Sciences - Nowy Targ, Poland 